\title{
Brief Analysis of Hierarchy of Human's Spiritual World
}

\section{Shitong Zhang}

Xinjiang Normal University, Xinjiang, China

\begin{abstract}
By studying human's spiritual world earnestly and comprehensively, you can learn that human's spiritual world is hierarchical. The spiritual world is an extremely complex dynamic system consisting of 4 interconnected hierarchies. The dynamic system is composed of cognitive system, dynamical system, reflection-controlling system and operating system. Human's spiritual world determines people's way of response and action. All the thoughts and behaviors of people are the result of all the subsystems in human spiritual world.
\end{abstract}

Key words: spiritual world; cognitive system; dynamical system; reflection-controlling system; operating system

\section{The Cognitive System of Human's Spiritual World}

The cognitive system of human's spiritual world provides humans resources of thoughts and basis of activities. It's the premise of other subsystems. Cognition is the reappearance of object in a concept form for the subject, and is the perception of the subject towards object. It contains whole process of feeling, consciousness, presentation, memory and thought, and can be further divided into two stages: perceptual knowledge and rational knowledge. The basic task of cognition is to study the identity of thought and existence, subject and object, cognition and practice, so as to form right understanding, hold the law of objective things followed by practice, and reach the fundamental goal of reforming the world. Knowledge is the fruit of cognition as well as the coagulation of practical activities. On the one hand, it coagulates as empirical knowledge and on the other hand as a cohesion of scientific theory knowledge.

With the purpose of self-survival and development, humans interact with natural world and human society at all times, and recognize the objective things through brain response, natural science knowledge and social science knowledge appear, and through long-term and painstaking self-exploration of human thinking activities research, people spread rational scientific knowledge. Cognition is structured and is continuously evolving and improving. Genetic epistemology raised by J. Piaget, a well-known Swiss psychologist and mathematical logician, lays emphasis on studying the structure. From the perspective of personal psychological development, he uses systematic and historical methods to reveal that thinking is the process of internalization of external behavior and formation of knowledge structure. Structural issues of cognition actually are the thinking mode issues of human brain. Thinking pattern is the combination of static thinking structure, thinking framework, dynamic thinking movement and thinking mode. The thinking pattern of human brain is the premise of new cognition as well as the result of previous cognition. People always recognize current things by the combination of relevant knowledge, experience and existing thinking pattern. Innumerable facts indicates that the more experience people have, the 
richer their knowledge, and the more perfect their way of thinking, the faster, better, and deeper people will understand reality. Strictly speaking, if people haven't formed thinking pattern in learning and practice, they neither can use general rule to learn about individual, nor make the individuals summarized to the general. As a result, people can't make any judgment to form cognition. The highest level of cognition is the view of the world, including fundamental and comprehensive world perspectives that can lead to the pinnacle of human mind and remain a key modulator of our mind and action.

Based on the generalization and summary of natural science and social knowledge, philosophy has become a systematic and theoretical worldview. It ultimately reveals the most basic laws of nature, society and thinking. Hence, philosophical world view can provide people with systematic world-based general cognition, theoretical rule and methodological guidance. It is a powerful tool for people to observe and reform the world. Being scientific in a philosophical world view enable people to enhance the principle, systematization, predictability and creativity in practice, so as to stand higher, see further, think deeper and act more efficiently in the world of cognition and reform. The fundamental role of cognition is to improve virtue by learning the principles of the world. So Lenin stated affirmatively, "only by using all the intellectual property people made to enrich your thinking, can you be a communist".

\section{The Dynamical System of Humans' Spiritual World}

The dynamical system of humans' spiritual world is the one provides motivation for people to recognize and practice. It is totally correct of the statement "Practice is the basis, source and motivation of cognition", which was mentioned repeatedly in philosophy textbooks in the past. However, the issue is not over. In addition, people may ask about what drives people to practice and recognize. What's the inner motivation? It's a vital theoretical issue which was attached great importance even from Marx to Lenin. They asked people to study the movement of recognizing oneself and one's independent activity.

The exploring of inner motivation drives the study of spiritual world into a higher level. The inner motivation of practice and cognition does not appear accidentally. It is a lasting one contains many factors to form a full system, which has levels and structures. It is a dynamic and complicated system composed of needs, ideals, faiths as well as emotions, wills and interests. Dissecting the dynamic system of humans' spiritual world, you can see that it uses needs as the driving force, ideals and beliefs as the spiritual support, and emotions, will and interests as the driving force to promote actual activities. Marx has elaborated on the issue of needs is the motive of humans practical activities in Economics-philosophy Manuscript in 1844. It conveys that humans' production has two standards, one connected with the external objects, the other with inner side which includes needs and aesthetic. In order to survive and develop, humans not only need to produce according to objective laws, which means in compliance with the external objects to solve the problems that conform to rules (the truth), but also need to be resolved in compliance with the inner needs (the kindness). Strictly speaking, people go for the truth because they pursue the kindness in practice. Just as Mao Zedong said, people's purpose in understanding the world is to transform the world. In Marx's opinion, the kindness which in compliance with the fundamental interest of the proletariat and broad masses of the people is the highest stage of meeting people's material culture needs. As a famous saying goes by Mao Zedong, "The basic principle of Marxism is to enable the people recognize their own benefit and unit to fight for it." Fundamentally, all the work we dedicate to is to strive for and defend people's benefit wholeheartedly.

Ideal and faith are the vital compositions of dynamical system of human's spiritual world. It is the strong spiritual support for cognition and practice. Faith is affirmation and belief towards something and theories of thoughts. People always carry out practice in accordance with faith and develop own ideal. Ideal is the rule-complied imagination of goals in practice, the reasonable choice of practice ending, and the dream and pursuit of beautiful future. Ideal is the unification of 
"already have" and "should have", that is, the combination of reality and future. There is a necessary connection between ideal and human practice. It is deep rooted in practice activities and is the inner requirement of reforming the world and creates beautiful life. The inner standard of human's production that Marx reveals includes the standard of inner needs and aesthetic. The inner standard of aesthetic is the one that people to comply with in doing practice from content to form. Philosophers, aesthetes and artists from home and abroad have put forward various opinions during long-term discussions on the nature of beauty. In the final analysis, the standard of beauty is the one complies with people's ideal and pursuit. Building under the rule of beauty means to practice according people's ideal and pursuit. Seen in this light, the subject and object in practice not only have the relationship between cognition and being recognized, but also the relationship between needs and satisfaction, and what's more, form the aesthetic relationship of appreciating and being appreciated, pursuing and being pursued based on the former two relationships. Mao Zedong once said, "People need some spirit", and the highest spirit is firm belief and lofty ideals. A person with firm beliefs and lofty ideals is real and noble. The dynamical system of humans' spiritual world also includes emotions, wills and interests. Healthy emotions, strong wills, interests beneficial for social development can stimulate people to accomplish tasks passionately and dauntlessly. Marx mentioned that the specialty of human is to act freely. So, where does the free action come from? It seems that it comes from the dynamic system of human spiritual world, which is composed of needs, ideals, faiths, wills, emotions, interests and hobbies to drive people to act freely. The dynamical system is the inner mechanism of free action.

From the perspective of the world view, the commanding height of cognition system combined with the needs, ideals, faiths, emotions, wills of dynamical system of spiritual world, will gradually develop into life pursuit till the view of life. It's an inevitable result of the combination, and a great gain of world view goes forward towards life domain. Lenin played an emphasis on indicating that, our main purpose is to exercise strict and complete life view of revolutionary during youth education. How to live and practise to make a life with no regrets? It's a question everyone should give an explicit answer. The reflection-controlling system of human spiritual world is a system that regulates and controls people's mind and behaviors. It lies in the deepest area of the spiritual world. Further more, it is a complicated system centered on selfconsciousness, which contains values, aesthetics, morality and ethics. As a Chinese saying goes "the one who knows others is wise, the one who knows oneself is clear-minded", which means it is the expression of wisdom to know others, but it is the true intelligence to know oneself. The so-called "knowing oneself" is to rethink one's own mind and behaviors.

Ancestors of human went through a long-term ignorant state in which subject and object were inseparable, and people had no ability of reflection in the state, which was actually the transition from animal to human. But since then, in longterm practice, humans have gradually separated the subject from the object and have the ability to reflect, which is one of the most important signs of mankind. From this point, we can conclude that the developing state of reflection-controlling system marks the level of mankind evolution. The evolution of human and animals are two different ways. The way of human development is far away from the animal world, which is mainly reflected in the increasingly complex spiritual world. It shows that cognition system, dynamical system and reflection-controlling system compose a constantly improved development chain. As a subject, people have the ability to reflect and can control their own mind and behavior. The purpose of reflection is control, so we call it a reflection-controlling system.

\section{The Reflection-controlling System of Human's Spiritual World}

The reflection-controlling system of human's spiritual world centers on self-consciousness, which is a side way of the mind. The mind of people is not only a realized existence, which reflects the object's character and external laws of the rule, but also includes self-consciousness with self as the identification object, reflecting the inner state and experience of the object. Only after the development of self-consciousness can subject realize the existence of oneself, self-judgment, 
self-examination, self-constraint, and to do self-respecting, self-reflection, self-warning and self-stimulation can be produced.

The reflection-controlling system contains view of values and concept of values. View of values or concept of values is the expression of values relationship between human and external things about needs and needs-meeting. The judgment of value or evolution of value reflects the relationship between the nature of object and the needs of subject. Its main purpose is to solve the issue of goal-meeting and make use of the function of object to provide services for subject. As the subject of cognition and practice, people make judges of object in compliance with concept of value, and can always take the results of most acceptable things confirmed by the masses as the goal of value pursuit, and use it to govern and control ones own mind and behavior. The concept of values contains views of the value of life closely related to the view of life. But they are not the same. The view of life means the goal and pursuit of life, while the view of the value of life is the reflection of concept of life value. The value of life contains two aspects mutually connected, one is the ability of bringing good to society and people which both have self value and inner value; the other is to give play to one's own ability, and make contribution to the society to realize the transformation of self-value into social value or external value. Therefore, the correct standard of judging the value of life should be the contribution the one has made to society and people, because contribution is the prerequisite for realizing self-worth and the fundamental mark of transforming inner value into external value. Contribution is also the objective standard to measure individual's social value, only those who devote their lives to social progress and people's happiness can have a precious and shining life.

The concepts of aesthetic and morality are essential in reflection-controlling system, it enables people to carry out duty much better. People should be good at distinguishing right from wrong, beauty and ugly. People will judge whether things are beautiful or ugly depending on the object's character and nature as well as people's concept of aesthetic. A noble person should be a guard of every beautiful thing, and should build an ideal personality and a beautiful heart according to the standard of beauty at all times. The concept of morality is the detector of people's mind and behavior, essence of society and the fulfillment of out self duty. Human nature is the sum of social relations. People in society work at different areas and form extremely complicated relationship. In order to maintain normal order of social production and life, it is necessary to adjust various social relations in a timely manner, usually by restricting people's behavior. Therefore, the relationship between morality and phenomenon and the concept of morality determined by economic relationship shows up to adjust people's relationship. The concept of morality of the reflecting-controlling system can make people rethink whether their thoughts and behaviors conform to the direction of social development, meet the requirement of times, whether they are suitable for their duties, and consciously complete tasks.

All in all, the reflection-controlling system is the detector and controller of people's mind and behavior, which enables people carry out their noble duty to achieve self-knowing, self-conscious, self-strong and till self-discipline. Marx has talked about this thoroughly. He said that the basis of morality is the self-discipline of human spirit, and the foundation of religion is the heterogeneity of human spirit.

\section{The Operation System of Spiritual World}

The operation system of spiritual world drives self action according to external standard, internal needs and aesthetic standards, which are inseparable. People is the subject of cognition and practice, and the practice is the activity of consciousness and goal. So the spiritual world includes not only cognition system, dynamical system, reflecting-controlling system, but also operating system that contains behaviors, the habit of behavior, and ability of behavior. Behavior is the movement of body, the habit of behavior is the way of proficient behavior and the ability is the expression of morality in a series of behaviors. In other words, it is whether people can express moral behavior and what the result is. It mainly 
supported by the behavior cultivation based on morality. Marx's philosophic science shows that practice is the base and bridge for people to realize their ideas. So what is the mechanism of this transition? Through a comprehensive and systematic analysis of the human spiritual world, we can find that the mechanism is an operating system. The operating system transforms ideas into objective things and reality through practice.

\section{The Conclusion of Hierarchy of Human's Spiritual World}

Through an overall view of cognition system, dynamical system, reflection-controlling system and operating system of human's spiritual world, we can see that they work separately and cooperatively, and can govern, drive and control people's mind and action. Furthermore, all the behaviors of people are under the governing of cognitive system and driven by dynamical system, which meets the requirements that reflect the purposeful practice of the control system.

\section{Conflicts of Interest}

The author declares no conflicts of interest regarding the publication of this paper.

\section{References}

[1] Lenin. (2017). Lenin Anthology (the 4th roll). Chinese People's Publishing House.

[2] Mao Z.D. (1977). Mao Zedong Anthology (the 5th roll). Chinese People's Publishing House.

[3] Lenin. (1959). Lenin Corpora (the 6th roll). Chinese People's Publishing House.

[4] Marx. (1982). The Complete works of Marx and Engles (the 1st roll). Chinese People's Publishing House. 